\title{
Entre el sexo y el espanto. Augusto y la literatura, o una Historia no Académica del primer emperador de Roma
}

Francisco García Jurado

\section{Universidad Complutense}

pacogj@ucm.es

Fecha recepción 09.01.2017 / Fecha aceptación 09.03.2017

\section{Resumen}

El propósito de este trabajo es poner las bases de lo que sería una «Historia no académica» (HnA) de la figura de Octavio Augusto en la literatura y el ensayo modernos, básicamente a partir de la segunda mitad del siglo XIX, a partir de tres parámetros esenciales:

a) No estamos ante una Historia programática, sino ante algo que acontece espontáneamente en diversas manifestaciones literarias.

b) Nos encontramos ante indagaciones personales, más propias de una elaborada hermenéutica que de una investigación factual sobre las «fuentes».

\section{Abstract}

The aim of this study is to lay the foundations of what would be a "Non-Academic History" (NAH) of the figure of Octavius Augustus in modern literature and essay, essentially since the second half of the 19th century, according to three essential parameters:

a) The NAH is not a programmatic History, but something that happens spontaneously in diverse literary manifestations.

b) We are faced with personal inquiries, more typical of elaborate hermeneutics than a factual investigation based on "sources". 
c) Se trata de una Historia que se articula mediante «tensiones», como pueden ser la regeneración frente a la decadencia, o el espanto frente a la felicidad. Por lo demás, el personaje literario del emperador está sujeto a tensiones con respecto a diversas figuras históricas, como pueden ser otros emperadores, los poetas de su época, o la propia figura de Cristo.

De esta forma, y de acuerdo con lo expuesto, las recreaciones más importantes de la figura de Augusto y su labor política aparecerán en relación con otros personajes, como es el caso de Virgilio. Para ilustrar mínimamente el proyecto de esta «Historia no académica» recurriré a tres autores significativos que pertenecen a momentos bien distintos: el pensador anarquista Pierre Joseph Proudhon, el novelista Hermann Broch y el ensayista Pascal Quignard.

\section{Palabras clave}

Octavio Augusto, Historia no Académica c) The NAH is articulated through "tensions", such as regeneration in the face of decadence, or fear in the face of happiness. Moreover, the literary character of the emperor is subject to tensions with respect to various historical figures, such as other emperors, contemporary poets and the figure of Christ himself.

In this way, and according to the above, the most important recreations of the figure of Augustus and his political work will appear in relation to other characters, as is the case of Virgilius. To illustrate this "Non-Academic History", I will draw on three significant authors who belong to quite different times: the anarchist thinker Pierre Joseph Proudhon, the novelist Hermann Broch and the essayist Pascal Quignard.

\section{Key words}

Octavius Augustus, Non-Academic History 


\section{Introducción}

Lo dejaré claro desde el principio: mi trabajo no a va obedecer al consabido modelo formulable como "Augusto en la literatura y el ensayo modernos». No voy a hacer un recorrido bibliográfico o meramente factual por las ocurrencias que Augusto ha tenido en las diferentes obras literarias de carácter más o menos histórico a lo largo de los siglos XIX y XX. Intentaré huir, asimismo, de las novelas históricas que tienen a Octavio Augusto como personaje principal $^{1}$, un tanto a la sombra del imprescindible ensayo de Ronald Syme titulado The Roman Revolution. Mi propósito en este trabajo es bien distinto. La formulación «Augusto y la literatura» podría constituir, con las ambigüedades acerca de a qué literatura nos referimos, la manera más adecuada de referirse a mi propósito. Obsérvese, asimismo, que he modificado la preposición «en» por la conjunción «y», de manera que ya no se considera algo o alguien («Augusto») dentro de un lugar («la literatura»), sino que se plantea la interrelación entre dos entidades cuya naturaleza va a definirse, precisamente, a partir de esa relación concreta, a saber, cómo se alimenta la figura «histórica» de Augusto de la propia literatura (antigua y moderna) y cómo esa propia literatura configura, asimismo, una figura literaria de Augusto, independiente de la visión histórica. Al hablar de «literatura», ya he señalado una buscada ambigüedad entre lo antiguo y lo moderno, es decir, entre autores como Virgilio y Hermann Broch, que constituirían los dos vértices de un triángulo ideal que se cierra con Augusto. Augusto y la creación literaria de su tiempo ya constituye, en sí misma, un tema discutido y discutible. Se suele hablar, dentro de la propia historiografía de la literatura latina, del llamado «Siglo de Oro» de las letras latinas, que se corresponde con el tiempo de Octavio Augusto. ¿Son los tiempos «pacificados» de Augusto una causa directa de este nuevo estado de cosas? Recordemos que a partir de Augusto algunos géneros, como la prosa histórica o la poesía, disfrutan de un momento de inusitado esplendor, al tiempo que la oratoria política cae en el desuso. Resulta significativo, a este respecto, que los grandes manuales de literatura latina,

1. «Storicamente la figura di Augusto non ha mai avuto particolare rilievo nella letteratura europea e il XX secolo non sembra fare eccezione; negli anni Ottanta sono comparsi tuttavia due romanzi piuttosto significativi dedicati al primo imperatore di Roma: Augustus: the memoirs of the emperor di Allan Massie (1986) e Klatscht Beifall, wenn das Stück gut war. Die geheimen Tagebücher des Göttlichen Augustus di Philipp Vandenberg (1988)». (F. Ursini, «Vite di Cesari. Le biografie romanzate degli imperatori romani dal 1980 a oggi», en B. Coccia (ed.), Il mondo classico nell'immaginario contemporaneo, Roma, 2008, 191). 
en particular el que conocemos como Schanz-Hosius², y que viene a ser una de las cumbres historiográficas de comienzos del siglo XX, hayan dividido la «Edad de Oro» en la etapa de Cicerón y la etapa de Augusto ${ }^{3}$. En particular, el manual de Schanz-Hosius establece un período formulable como «La literatura romana desde el final de la República hasta la muerte de Augusto (30 a.C.-14 d.C.)», dejando ese período desgajado, incluso desde el punto de vista físico (pues constituye un tomo distinto), de la etapa precedente, es decir, la etapa republicana. Hay, por tanto, una intención política de conferir al período imperial una entidad propia incluso desde el punto de vista literario.

De esta forma, como ya he señalado, mi planteamiento está basado en una triple relación establecida entre Augusto, ciertos autores antiguos y ciertos autores modernos que crean el marco adecuado para poder indagar en lo que desde hace más de diez años vengo denominando una «Historia no Académica» (HnA) de la literatura grecolatina desde las literaturas modernas. Mi propósito en este trabajo es fundamentar las bases para una Historia de estas características en torno a la figura de Augusto, donde interactúa la literatura desde un doble nivel: los hipotextos, generalmente textos antiguos, que alimentan nuevos textos referentes a Augusto, y la posible relectura de tales hipotextos a partir de nuevas claves hermenéuticas por parte de los autores modernos.

La figura literaria de Augusto, tal como aparece dentro de ciertas obras clasificables como literarias y ensayísticas a un tiempo, es fruto de un riquísimo proceso intertextual, al tiempo que interpretativo. El marco teórico de esta $\mathrm{HnA}$ presenta las siguientes características:

- No se trata de una Historia programática, sino que acontece de manera espontánea. Esto no quiere decir que los creadores no puedan tener conciencia de estar llevando a cabo una $\mathrm{HnA}$, pero es, sobre todo, el estudioso quien crea ese marco de estudio al analizarlo y conferirle, por tanto, una forma más precisa y consciente. En muchos casos, esta HnA servirá de avanzadilla para desarrollar o experimentar con ciertas visiones de Augusto que desde el punto de vista de un ensayo estrictamente académico serían inadmisibles, al menos hasta cierto momento. Por otra parte, veremos que la figura de Augusto en sí misma es tan pertinente dentro de este marco como su huella histórica, es decir, las consecuencias de la acción de su principado. Tal huella se proyecta en el futuro, como si el paso de Augusto por la Historia supusiera un radical corte entre el tiempo anterior y el posterior. Se cumple de este modo el sueño de una nueva edad, aunque no necesariamente mejor que la anterior.

2. M. Schanz - C. Hosius, Geschichte der Römischen Literatur bis zum Gesetzgebungswerk des Kaisers Justinian von Martin Schanz. Vierte neubearbeitete Auflage von Carl Hosius, Múnich, 1920-1927.

3. F. García Jurado, "Los manuales escolares de literatura latina del 27: enseñar bajo una dictadura (García de Diego, Yela Utrilla, Galindo Romeo y Echauri)", Ágora. Estudos classicos em debate, 17, 2015, 425-435.

4. F. García Jurado, "Melancolías y 'clásicos cotidianos'. Hacia una historia no académica de la literatura grecolatina en las letras modernas", Tropelías, 12-14, 2001-2003, 149-177 (153-161). 
- Su método de indagación es predominantemente hermenéutico, frente a la orientación positiva de los planteamientos académicos, basada en el estudio de las llamadas «fuentes». La recreación literaria de Augusto goza de mayor libertad y licencias que la estrictamente histórica. En este sentido, la aproximación que Hermann Broch hace con respecto a la figura de Virgilio, «aprehendiendo» globalmente las circunstancias vitales del personaje, es un ejemplo paradigmático de este método que tanto debe a la formulación de las Ciencias del Espíritu tal como las formuló Wilhelm Dilthey ${ }^{5}$. Así pues, desde su particular aprehensión de Virgilio y las razones por las que quiso (o no) quemar la Eneida, el autor austriaco nos ofrece un admirable y tenso retrato de Augusto en el libro tercero de su novela La muerte de Virgilio $^{6}$. Asimismo, como fruto de una profunda orientación hermenéutica inspirada en Maurice Blanchot, tenemos la inquietante reflexión que Pascal Quignard hace acerca de las consecuencias que tuvo la política augustea sobre la moral sexual romana a partir de las propias pinturas pompeyanas de la Casa de los Misterios.

- La HnA se articula en torno a tensiones que confieren a tal Historia una dimensión sistémica o recurrente. De esta forma, los retratos literarios del emperador vienen motivados por polaridades diversas, como puede ser la del gran estadista frente al tirano (Syme), la regeneración frente a la decadencia (Proudhon), la trascendencia frente a la muerte (Broch), o bien el espanto frente a la felicidad (Quignard). El propio papel literario de Augusto como emperador plantea, asimismo, tensiones con respecto a otros emperadores que desde el punto de vista dramático han sido más productivos, como Calígula, Nerón o Heliogábalo, dado que éstos, por su carácter disoluto, alimentaron los imaginarios decadentes. Por ejemplo, en la novela de Graves titulada Yo Claudio, Augusto aparece en función del protagonista y también futuro emperador que da título a la novela. Asimismo, el hecho de haber compartido etapa histórica con poetas de la talla de Virgilio, Horacio u Ovidio supedita su figura casi siempre a la primacía de tales poetas. Ya dentro de otra tensión, la planteada entre paganismo y cristianismo, tan productiva para cierta literatura de

5. «Pero hay que afirmar, además, que fuera de las unidades psíquicas que constituyen el objeto de la psicología, no se dan hechos espirituales para nuestra experiencia. Pero como la psicología no contiene en modo alguno todos los hechos que son objeto de las ciencias del espíritu, o -lo que es igual- que la experiencia nos permite aprehender en las unidades psíquicas, resulta de esto que la psicología solo tiene por objeto una parcela de lo que sucede en cada individuo particular. Por tanto, solo por abstracción puede separarse de la ciencia total de la realidad histórico-social, y solo puede desenvolverse en constante relación con ella» (W. Dilthey, Introducción a las ciencias del espíritu. Prólogo de José Ortega y Gasset, Madrid, 1986, 74-75).

6. J.L. Vidal, "Por qué Virgilio quería quemar la Eneida..., si es que quería", Humanitas in honorem Antonio Fontán, Madrid, 1992, 479-484. 
carácter histórico a finales del XIX, Augusto puede quedar contrapuesto y eclipsado con respecto a la figura de Cristo $^{7}$.

A partir de tales características, creemos que es posible hablar de una visión alternativa con respecto a la figura histórica de Augusto que atienda a unas claves diferentes, de naturaleza literaria y basadas, más que en la mera factualidad de los datos, en una elaborada hermenéutica. Naturalmente, existen unos límites difusos entre lo estrictamente académico y lo literario, y a menudo el ámbito no académico se convierte en vanguardia de lo alteracadémico. Así ocurre con la visión pesimista que desarrolla Hermann Broch en su novela La muerte de Virgilio (1945), y que tanto peso tendrá luego en la llamada «Escuela de Harvard». También se puede dar el caso inverso, donde una obra académica fundamental, como The Roman Revolution de Ronald Syme, publicada en unas fechas nada inocentes (1939), inspira y condiciona futuras recreaciones literarias acerca de Augusto. De esta forma, si dejamos en un segundo plano las aportaciones literarias más esperables, como las propias novelas históricas sobre Augusto, es interesante indagar en la presencia de este personaje dentro de ciertas obras que no lo presentan más que en función de otras figuras también históricas, como los poetas Virgilio y Ovidio. Asimismo, ya he apuntado anteriormente que tan importante como el personaje de Augusto es su «huella» histórica, es decir, todo aquello que su principado dejó a la hora de cambiar el mundo, incluido el nuestro. Acerca de este aspecto, tenemos dos autores franceses, pertenecientes a etapas muy diferentes, el pensador social Proudhon y el ensayista Quignard, que nos aportan claves precisas acerca de este hecho.

Como ya he indicado anteriormente, no es mi intención hacer un «recuento» de las novelas, en especial, históricas, que han utilizado a Augusto como personaje. Mi trabajo en el ámbito de la HnA me conduce básicamente a tres autores significativos que pueden ilustrar esta relación de Augusto con la literatura y el ensayo:

- En calidad de precursor de tales planteamientos alteracadémicos destaca Proudhon y su ensayo sobre Virgilio (1858), donde desarrolla ideas como la de la revolución, el universalismo y el cristianismo en calidad de aspectos propios de la etapa augústea (1858).

- Hermann Broch y su novela titulada La muerte de Virgilio (1945), donde se ofrece uno de los retratos de Augusto que me parece más interesante y vital: mientras

7. «Shakespeare dedicó tragedias a Julio César y Marco Antonio, pero no a Augusto. Es un personaje importante, pero también secundario, en Yo, Claudio, de Robert Graves, así como en la versión de Cleopatra que protagonizó Elizabeth Taylor. Sin embargo, el primer emperador de Roma, el hombre que acabó con la República aunque conservó hábilmente sus instituciones vacías de poder, fue cualquier cosa menos un personaje secundario de la historia [...]» (G. Altares, «Augusto, emperador el presente», El País. Babelia 8 de noviembre de 2014, 2). El artículo contiene una entrevista a Adrian Goldsworthy, autor de Augusto. De revolucionario a emperador, Madrid, 2014. 
Augusto busca en la Eneida su trascendencia histórica, Virgilio considera su obra inacabada como una manera de poder entender mejor la propia muerte.

- Pascal Quignard y su ensayo acerca del sexo y el espanto (1994), que desarrolla las consecuencias de la política moral y sexual de Augusto a partir del análisis de los frescos pompeyanos. Asimismo, me parece sumamente sugestivo el retrato literario que nos ofrece de Augusto en su novela Albucius (1990).

Cada obra representa, a su manera, el espíritu de una época, como es la segunda mitad del siglo XIX, donde la literatura augústea o del llamado Siglo de Oro se está viendo sometida a una revisión peyorativa, los años subsiguientes a la Segunda Guerra Mundial, donde Virgilio va a representar, con su muerte, el fin de Occidente, y los años finales del siglo XX, sujetos a novedosas revisiones desde el punto de vista de la moral.

\subsection{Proudhon: regeneración y catolicidad}

El cristianismo y su idea de «catolicidad» vendrían a ser una consecuencia de la etapa histórica presidida por Augusto. Esta sería una de las sorprendentes interpretaciones que hace el pensador social anarquista Proudhon, particularmente en su libro titulado De la justice dans la révolution et dans l'Église ${ }^{8}$, publicado por primera vez en 1858 , y al que he dedicado ya un estudio previo ${ }^{9}$. La tesis fundamental de este libro es que la Eneida es la obra que representa la regeneración de Roma y de la humanidad, lo que permite indagar al autor en la capacidad revolucionaria que una obra literaria puede tener a la hora de cambiar el signo de los tiempos.

El aspecto más polémico en esta obra reside probablemente en la relación que Proudhon establece entre Virgilio y el cristianismo. Esta relación ya había sido avanzada escuetamente unas páginas antes de entrar en materia: "parler de Virgile, c'est parler du christianisme» ${ }^{10}$. Este aserto en realidad no comienza a comprenderse hasta que no llegamos a lo que Proudhon considera como la revelación del progreso y de la catolicidad del género humano ${ }^{11}$, expresada mediante la unificación de cultos que Augusto lleva a cabo en el panteón romano. Habida cuenta, por tanto, de que la universalidad o catolicidad de la religión parte de esta unificación de cultos dictada por Augusto, cabe ahora preguntarse qué es lo que se esconde tras el aserto que identifica sin más a Virgilio con el cristianismo. Cabría pensar que Proudhon considera a Virgilio como un autor «precristiano», según han querido ver tantos comentaristas, o más bien establece una identificación total entre Virgilio y el cristianismo, de manera que lo que Proudhon quiere darnos a entender es que el cristianismo nace precisamente en Virgilio. La

8. P.J. Proudhon, De la justice dans la révolution et dans l'Église. Neuvième Étude. Progrès et décadence, Bruxelles, 1860, 118-190. Las citas de Proudhon se harán a partir de esta edición.

9. F. García Jurado, "La Eneida como utopía regeneradora: Pierre-Joseph Proudhon”, Studia philologica Valentina 16, n.s. 13, 2014, 51-68.

10. P.J. Proudhon, De la justice... op. cit., 129.

11. P.J. Proudhon, De la justice... op. cit., 135. 
idea de que el cristianismo puede concebirse como una transposición del mundo pagano está bien asentada en el pensamiento anarquista ${ }^{12}$.

Es cierto que ya desde antiguo se había puesto en relación a Virgilio con el cristianismo de diferentes maneras. Parece que la gran diferencia con respecto a lo que propone Proudhon no es tanto ver en el autor latino a un precursor de la religión cristiana, en especial a tenor de lo que nos cuenta en su premonitoria égloga cuarta, como en considerar la religión cristiana algo que se inspira en el espíritu renovador de Virgilio y de su época para cobrar altura universal. Sin embargo, esta renovación consiste en el paradójico juego de lo que podemos considerar la victoria en la derrota. Así pues, la diosa Juno, siempre hostil a Eneas, es derrotada en la persona del caudillo Turno cuando éste muere a manos de su antagonista troyano; sin embargo, Juno sale vencedora al encontrar en aquellas tierras del Lacio un nuevo lugar para su culto. De igual forma, una vez los troyanos se refugian en Italia, éstos pierden su nombre y su nacionalidad ${ }^{13}$. En este sentido, Virgilio parece decir a los romanos que la civilización se comunica. De todo este complejo estado de cosas, según Proudhon, habría bebido el propio cristianismo:

A côté de ces idées mères, qui forment la charpente et l'originalité de l'Enéide, idées dont le christianisme s'est paré plus tard comme s'il les eût trouvées de son fonds, il convient d'en rappeler quelques autres, d'une importance secondaire mais qui n'en font pas moins du poème une œuvre unique en son espèce, sans modèle, comme l' Iliade, et, comme l' Iliade, inimitable. ${ }^{14}$

Entendida, pues, la Eneida, como una obra inspiradora del cristianismo, el panteón de Augusto no habría sido más que la antesala del monoteísmo cristiano:

12. El geógrafo y también anarquista Elisée Reclus (1830-1915) escribe en su magna obra El hombre y la tierra que la era cristiana no era otra cosa que una transposición de la era de Augusto: «Verdad es que esta era, denominada cristiana, fue después considerada como coincidente con la fecha, sea de la encarnación, sea del nacimiento de Jesucristo. Cuando fue propuesta por primera vez por el monje Denys le Petit, pronto hará catorce siglos, en el año de Roma 1278, que vino a ser el año 525 del nuevo calendario, los fieles católicos la acogieron por espíritu religioso, y gracias a este mismo espíritu reemplazó poco a poco oficialmente, en los documentos políticos y administrativos, lo mismo que en la vida ordinaria, las eras precedentemente practicadas, seleuciana, juliana o diocleciana. Pero faltaba absolutamente casi todo documento histórico sobre la vida de Jesucristo; el inventor de la era nueva no pudo establecerlo, y aun con un error probable de algunos años, sino por medio de fechas suministradas por la historia contemporánea en la vida de Augusto y de Tiberio: en los anales mismos del Imperio fue preciso buscar todos los elementos del nuevo cómputo. En realidad la era cristiana no es sino la era «augustiana», lo mismo que los antiguos meses de quintilis y de sextilis se convierten en los meses de julio y de agosto, o «Augusto». La era según la cual contaban los españoles todavía en el siglo XIV databa francamente de Augusto y celebraba la reunión de la península Ibérica toda entera al imperio romano.» (E. Reclus, El hombre y la tierra. 3. Historia antigua, Madrid, Doncel, 1975, 190-191).

13. «Le refuge est accordé aux Troyens en Italie; mais ils perdent leur nom et leur nationalité.» (P.J. Proudhon, De la justice... op. cit., 136).

14. P.J. Proudhon, De la justice... op. cit., 136. 
[...] le monde cherchait une foi, une loi, un dieu. Auguste avait donné le signal du mouvement en centralisant les cultes et en fondant le Panthéon. Si l'Orient, par son esprit théologique et ses innombrables superstitions, était le point de départ de ce nouveau courant d'idées, Rome en était le foyer. Que la nouvelle religion prît son point de départ en Espagne, dans la Gaule, la Grèce, l'Égypte ou la Syrie, peu importait : elle devait se faire toute à tous, synthétiser, du mieux qu'elle pourrait, toutes les croyances anciennes et nouvelles: elle devait, avant tout, être romaine. ${ }^{15}$

Tales ideas no dejaban de resultar inadmisibles, incluso heréticas, para los pensadores católicos. Sin embargo, Proudhon ejerció un atractivo influjo, sobre todo porque conectó con el afán regeneracionista tan característico del pensamiento de finales del siglo XIX y comienzos del XX. Como puede comprobarse, apenas he mencionado el nombre de Augusto, aunque en realidad no he dejado de hablar de él. De hecho, la obra de Proudhon resalta un aspecto clave de Augusto, como es el de su huella histórica para la posteridad. Es algo que también podremos ver en la obra de Pascal Quignard, aunque en este caso la visión de la herencia de Augusto será ciertamente mucho más negativa.

Proudhon parte de un argumento silente y fundamental, como es considerar la obra de Virgilio en clave de un fiel reflejo de la etapa augústea, pues la considera de hecho como su propia encarnación. Esta equivalencia, sin embargo, es la que va a cuestionar Broch cuando configura literariamente un poeta que se resiste a las insistencias del emperador a la hora, precisamente, de dar por concluida su Eneida.

\subsection{Broch: la transcendencia frente a la muerte a través de la literatura}

La verdadera historia -pensó- despierta la nostalgia por un pasado que no existe más y que es en vano tratar de resucitar. De ese pasado queda en cambio la noción de muerte que triunfadora se impone a nuestros ojos. Frente a ella irrumpe un vacío metafísico imposible de llenar, que no es otra cosa que el pánico de la existencia que se sabe efímera; pensó también -no sin cierto sosiego- que la idea más perfecta de libertad es la muerte, por la que pasaremos todos, y esa idea pareció serenarlo un poco y hasta creo que sonrió al madurarla en su interior. (Hugo Bauzá, Virgilio. Memoria del Poeta. Una autobiografía espiritual, Buenos Aires, 2011, 157)

La novela de Hermann Broch gira en torno a un tema acaso manido, mas sumamente ambiguo, como son las razones por las que Virgilio quiso quemar la Eneida, si acaso quiso quemarla de veras. En su trabajo ya citado ${ }^{16}$, José Luis Vidal ha revisado la cuestión desde los testimonios positivos procedentes de la Vita de Suetonio-Donato hasta la interpretación puramente hermenéutica de Broch. De manera particular, el testimonio de Suetonio-Donato

15. P.J. Proudhon, De la Justice... op. cit., 137.

16. "Quisiéramos ahora acercarnos a las intenciones de Virgilio por caminos distintos, sin duda menos positivistas, pero no menos respetuosos», J.L. Vidal, "Por qué Virgilio quería quemar la Eneida..., si es que quería”... op. cit., 480 . 
resulta, en su esquematismo, muy gráfico en lo que respecta a la actuación de Augusto con respecto a la Eneida: ${ }^{17}$

12 Por otra parte, cuando Augusto le ofreció los bienes de un desterrado, no se atrevió a aceptarlos

[...]

$21 \mathrm{Al}$ final empezó la Eneida, un tema variado y múltiple, y semejante a ambos poemas de Homero; además con personajes y hechos griegos y latinos en común, y en el que estaría contenido lo que más deseaba, el origen de la urbe romana y el de Augusto a la vez.

$[\ldots]$

27 Cuando regresó Augusto después de la victoria de Accio y se detuvo en Atella para recuperarse de la garganta, Virgilio le leyó las Geórgicas durante cuatro días continuos, tomando Mecenas turno para leer, cuantas veces era interrumpido él mismo por la indisposición de la voz.

$[\ldots]$

31 Y Augusto - pues casualmente estaba lejos de Roma por la campaña de Cantabria-, le pidió en cartas suplicantes y también, en broma, amenazadoras que «de la 'Eneida' le fuera enviado», según sus palabras, «o el primer esbozo del poema, o la parte que quisiera». 32 Sin embargo, mucho después, cuando finalmente había preparado la materia, Virgilio le recitó únicamente tres libros, el segundo, el cuarto y el sexto, pero éste con gran impresión en Octavia, de la que se cuenta que, estando presente en la recitación, desfalleció ante aquellos versos acerca de su hijo: «tú serás Marcelo», y fue reconfortada con dificultad.

$[\ldots]$

35 A los 52 años de edad, con la intención de dar la última mano a la Eneida, decidió irse a Grecia y a Asia, y en tres años continuos no hacer nada más que corregirla, para que el resto de su vida estuviera libre sólo para la filosofía. Pero como al emprender su viaje se hubiese encontrado en Atenas con Augusto, que regresaba a Roma proveniente de Oriente, y decidiera no abandonarlo e inclusive regresar junto con él, mientras conoce la ciudad vecina de Megara con un sol muy ardiente, contrajo una enfermedad y, al no interrumpir el viaje por mar, empeoró, de modo que llegó a Brindisi bastante más grave, donde a los pocos días murió, el 21 de septiembre, siendo cónsules Cneo Sentio y Quinto Lucrecio.

$[\ldots]$

37 Nombró herederos, por la mitad de sus bienes, a Valerio Próculo, hermano de diferente padre; por la cuarta parte, a Augusto; por la duodécima parte, a Mecenas; por lo restante a Lucio Vario y a Plocio Tuca, quienes, después de su muerte, revisaron su Eneida por orden del César. $[\ldots]$

41 Mas Vario publicó la Eneida con autorización de Augusto, pero enmendada ligeramente, de modo que él dejó incluso los versos incompletos tal como estaban. Muchos, habiendo intentado completarlos tiempo después, no pudieron hacerlo, debido a la dificultad, porque casi todos los hemistiquios, en su obra, están en absoluto y perfecto sentido, excepto aquel: «quem tibi iam Troia».

17. M. Elena Montemayor Acebes, "Suetonio, Vida de Virgilio", Nova Tellus, 27, 2009, 205-235. 
Del testimonio de esta vita se deduce que Augusto siempre estuvo presente durante la composición y posterior edición de la Eneida. La noticia que nos da Suetonio acerca de las amenazas que «en broma» profería Augusto a Virgilio para que terminara su obra poco aclaran acerca de la relación entre el poeta y el emperador, aunque no impiden que podamos imaginarlas como conflictivas. Así las cosas, una de las escenas centrales de la novela titulada La muerte de Virgilio tiene que ver con un tenso diálogo entre el poeta y el emperador, que acude en Brindisi a las estancias donde se encuentra alojado Virgilio con la intención de arrebatarle el manuscrito de la Eneida. Este diálogo es el que articula la conocida interpretación de «Virgilio frente a Augusto» que luego ha hecho suya la así llamada «Escuela de Harvard», a diferencia de la actitud favorable a Augusto sostenida generalmente por el mundo académico europeo $^{18}$. La muerte de Virgilio, con la consiguiente entrega definitiva de su Eneida para Augusto y la posteridad, no parece significar otra cosa que la eternidad del propio Augusto y la instrumentalización del poema épico para su propia gloria. Se trataría de una apropiación parecida a la que es posible apreciar en el mismo monumento del Ara Pacis, que, contemplado desde la esquina derecha de su fachada delantera, permite ver al propio Eneas y, en el lateral, también a Augusto, ambos togados y en acto de llevar a cabo un sacrifico ${ }^{19}$.

A este respecto, resulta clave la intensa y tensa conversación que mantiene un moribundo Virgilio con un Augusto todavía joven dentro del libro tercero de la novela de Broch, donde el emperador deja claro a Virgilio que su Eneida ya no le pertenece. Es interesante observar que el texto de Broch parte de un pasaje clave de la Eneida, precisamente la referencia a la batalla de Accio en la descripción del escudo de Eneas (VIII 626-728). Augusto se lo recuerda a Virgilio de esta manera:

- Hay pocas cosas tan dignas de mi memoria. ¿No fue poco después de regresar yo de Egipto, cuando me sometiste el primer esbozo de la epopeya?

-Tú lo has dicho.

-Y en el centro del poema, verdaderamente centro y clímax del poema, en el centro del escudo de los dioses que concediste a Eneas, ha[s] puesto la descripción de la batalla de Accio.

-Así lo hice. El día de Accio fue la victoria del espíritu romano y sus costumbres sobre las oscuras fuerzas de Oriente, la victoria sobre el oscuro misterio que acaso se había apoderado de Roma. Esta fue tu victoria, Augusto.

$-¿$ ¿Sabes el pasaje de memoria?

18. "Although almost none of Virgil's poetry is in the first person, it is not surprising that Virgilian scholarship and criticism has from first been marked by a strong biographical interest. This makes for good novels (Hermann Broch's The Death of Virgil is a landmark in the history of the modern novel), but bad criticism. Despite the demise of the kind of biographical criticism that used literary texts as sources for reconstructing the life of the poet, this biographical interest survives in the form of obsession, still burning for some critics, to determine Virgil's personal attitude towards Augustus. This concern is implicit in much of the debate between the so-called 'Harvard' (anti-Augustan) and 'European' (pro-Augustan) schools of critics». (Ph. Hardie, Virgil, Oxford, 1998, 2).

19. F. García Jurado, "El triunfo de Augusto. Ara Pacis", Historia National Geographic, 135 marzo de 2015, 58-67. 
- ¡Cómo podía saberlo! Mi memoria no alcanza la tuya.

- ¡Oh, ningún engaño era posible! Inequívocamente el Augusto había dirigido los ojos hacia el cofre del manuscrito, y los mantenía fijos en él: ¡oh, no era una ilusión, había venido a quitarle el poema! (Hermann Broch, La muerte de Virgilio, Madrid, 1995, 305)

Podemos observar también cómo Broch plantea una interesante dicotomía entre la memoria y la escritura (La muerte de Virgilio, 306), dado que Virgilio recita de memoria el pasaje clave, el que se refiere a la batalla de Accio (La muerte de Virgilio, 307). Sin embargo, Augusto quiere obtener la materialidad de este poema, es decir, su manuscrito. Luego deriva la conversación hacia el tema de la gratitud que Virgilio siente por Augusto (La muerte de Virgilio, 309), gratitud que, por otra parte, según el sentido pragmático que Augusto siente por las cosas, no debe terminar simplemente en nada. Resulta muy interesante la contraposición que se establece entre la obra artística y la labor de Estado (La muerte de Virgilio, 311), dado que mientras Virgilio cree que lo que sobrevivirá a la memoria es la labor política de Augusto, éste ve en la Eneida, es decir, en el arte, su verdadera supervivencia. Augusto recita, por su parte, un nuevo pasaje de la Eneida (La muerte de Virgilio, 313). La cuestión esencial llega cuando Augusto pregunta sin ambages a Virgilio por qué quiere destruir su Eneida ( $L a$ muerte de Virgilio, 317) y comienza una disquisición acerca del «conocimiento de la muerte», cercana a la propia orientación órfica de Virgilio (La muerte de Virgilio, 320). La discusión entre el emperador y el poeta deriva ahora a plantear la obra de Augusto como metáfora del pueblo romano (La muerte de Virgilio, 327), en una idea que nos recuerda mucho a lo expresado por Jakob Burckhardt en su estudio sobre el Renacimiento, a saber, la idea del Estado como una obra de arte (La muerte de Virgilio, 336-338). Tras una airada discusión y el soberano enfado de Augusto, Virgilio accede finalmente a que se lleven a Roma el cofre que contiene la Eneida. Augusto ya no pierde más tiempo en discutir, es más, lamenta haber perdido tantas horas en disquisiciones que ni tan siquiera le interesan. Su mundo es el real y su propósito la trascendencia. Precisamente, es esa realidad, convertida ahora en hiperrealismo, lo que Quignard acabará convirtiendo en el augusto mundo de la sordidez.

\subsection{Quignard: la moral sexual de Augusto, o el espanto}

Si Proudhon había ensayado hábilmente una idea de cambio radical para la humanidad durante el principado de Augusto, con el propio nacimiento del Cristianismo dentro de su seno, Pascal Quignard va a indagar en este sentido, pero con fines bien diversos. En su original ensayo titulado El sexo y el espanto ${ }^{20}$, Quignard trata acerca de las consecuencias de una moral impuesta por Augusto que él ve plasmada, decenios después de la muerte del emperador, en las pinturas pompeyanas, tal como quedaron tras la erupción del año 79 de nuestra era:

Trato de comprender algo incomprensible: el traspaso del erotismo de los griegos a la Roma imperial. Esa mutación no ha sido pensada hasta ahora, no tanto por una razón que ignoro

20. P. Quignard, El sexo y el espanto, Trad. de Ana Becciú, Barcelona, 2005. 
como por un temor que concibo. La metamorfosis del erotismo alegre y preciso de los griegos en melancolía aterrada tuvo lugar durante los cincuenta y seis años del reinado de Augusto, que reorganizó el mundo romano bajo la forma del imperio. Esa mutación tardó solo unos treinta años en imponerse (del año 18 a.C. al 14 d. C.), y sin embargo aún nos envuelve y domina nuestras pasiones. El cristianismo no fue más que una consecuencia de esa metamorfosis: retomó, por así decirlo, el erotismo en el estado en que lo habían reformulado los funcionarios romanos que promovió el principado de Octavio Augusto y que el Imperio, en los cuatro siglos siguientes, se vio obligado a multiplicar con obsequiosidad. (El sexo y el espanto, 8-9)

Ese mundo donde el sexo, sujeto a una férrea moral, se convierte en espanto, se define por lo que Quignard entiende que es la estética de la sordidez, y mediante la cual retrata al propio Augusto en lo que no deja de ser una vida imaginaria. Es curioso tanto el lugar como la manera tan inusitada por la que comenzó Quignard a pensar en Augusto, precisamente sentado en un banco junto a la muralla del palacio imperial de Tokio. Así nos lo cuenta él mismo en su obra titulada Albucius $^{21}$ :

En junio de 1989, yo estaba solo y hastiado. Compuse sesenta de estas páginas sentado en un banco de madera, entre enormes cuervos funerarios, sobre las murallas del jardín imperial de Tokio.

En el estanque que estaba al pie de las murallas había una pequeña tortuga que alzaba su cabeza fuera del agua aproximándose al pilar de madera cercano a la orilla. La cabeza dejaba atrás una estela. Una y otra vez la masa de su cuerpo se arrastraba hacia el fondo. Miré la cabeza verde, vieja, implacable, escamosa. Me dije: ‘'Claro, es Augusto!'. Era evidente. Ahora me sorprende. El país donde las puertas de los taxis se cierran solas y donde la gente se quita los zapatos para comer me sepultó en una Roma imaginaria más viva y más irrigada de sangre que los rostros de los bonzos zen con los que había venido a conversar. (Albucius, 9-10)

Esta «visión» de Augusto tan lejana e inesperada se va a compaginar con la lectura de la obra de Séneca el Viejo y del propio testimonio que Suetonio nos ofrece de Augusto para crear una imagen sórdida, acorde con los parámetros establecidos en su ensayo ya citado, $E l$ sexo y el espanto. Cabe destacar, en este sentido, que Quignard hace con el «hipotexto» de Suetonio (mejor que «fuente») algo parecido a lo que Borges propone en su cuento «Pierre Menard, autor del Quijote». Se trata de una relectura que puede parecer literal, pero que reconduce el texto originario a la propia estética de la sordidez.

Gayo Albucio Silo, un raro autor latino de la época de Augusto, es uno de tantos cuya obra se ha perdido para siempre. Leopoldo Alas Clarín evocaba en su cuento "Vario» a un poeta cuya obra había desvanecido la incuria del tiempo, con la paradoja de haber sido, asimismo, Vario, quien salvó la Eneida para la posteridad. El contemporáneo de Clarín, Marcel Schwob, recrea en la vida imaginaria de Lucrecio a un poeta que muere enloquecido sin haber escrito ni tan siquiera la obra que lo consagró para la posteridad, el poema científico

21. P. Quignard, Albucius, Trad. de Betina Keizman, Buenos Aires, 2010. 
titulado Sobre la naturaleza de las cosas. Sobre Albucio, y gracias a los testimonios de Séneca el Retor, conservamos algunos retazos de su existencia y su obra. Ambas son las que más o menos imaginariamente se propone reconstruir Pascal Quignard. Quignard conoce las lenguas clásicas (de hecho, ha traducido la Alejandra de Licofrón el Oscuro), por lo que sus reelaboraciones están bien fundamentadas. Como vengo diciendo, el gran asunto de Albucius es indagar en algo tan espeluznante como la «belleza de la sordidez». Cayo Albucio Silo es inventor de pequeñas e impactantes obras retóricas que, confundidas con las de Séneca el Retor y otros autores de su época, tienen como fin la controversia. Esclavos que mueren torturados, hijos pródigos y mujeres sospechosas de adulterio pueblan el oscuro mundo de Albucio, donde la fealdad moral y estética crea una extraña forma de grotesca belleza. Quignard se propone no sólo inventar la vida de Albucio, sino reconstruir 53 de sus piezas oratorias, pequeños episodios donde suele exponerse una causa judicial imposible. La obra de Quignard, en definitiva, parece estar escrita para servir de egregio ejemplo de la historia no académica que propongo. Vamos a centrarnos finalmente en el texto que dedica al emperador Augusto, y que constituye por sí mismo uno de los capítulos de la obra (Albucius, 89-94). Como he adelantado, está construido sobre pasajes de la vida que Suetonio dedicó al emperador, además de diversos textos tomados, entre otros, de Séneca el viejo. A este respecto, es significativo este peculiar uso sórdido del lenguaje que Quignard atribuye a Augusto:

El emperador reprochaba a Quinto Haterio que hablara demasiado rápido y decía: - Haterius noster sufflaminandus est. (Nuestro Haterio necesitaría que lo frenen).

A decir verdad, el emperador no apreciaba mucho la cadencia ni la superabundancia de Haterio. A veces se burlaba. Por la corte circulaba un chiste. Un día, declamando sobre un joven esclavo que negaba haber entregado sus favores al amo, Haterio había dicho:

-Impudicitia in ingenuo crimen est, in servo necessitas, in liberto officium. (En un hombre libre, la falta de pudor es un crimen; en un esclavo, una obligación; en un liberto, un servicio).

De inmediato, el emperador y toda la corte se sirvieron de la frase. No se decía más: «Préstame tu culo»; decían: non facis mihi officium? («¿Me prestarías un servicio?»). Durante el resto de su vida, el emperador no usó más las palabras «depravados» u «obscenos», y las sustituyó por la palabra officiosi («gente servicial»). (Albucius, 90)

Quignard crea una suerte de collage de referencias diversas para describir a Augusto:

Era un hombre miedoso, cruel, elocuente, civilizado. Le gustaba arrancar los ojos con sus propias manos. Odiaba el ladrillo. Buen letrado, nunca se fiaba de las críticas ni de los profesores. En la cuestión de la lengua, era muy exigente. Siempre disfrutaba del placer de visitar las bibliotecas privadas o públicas, y de permanecer en ellas durante horas. Amaba a Roma, aún con mayor vehemencia por no ser de origen romano. Le apasionaban las cosas antiguas y las raíces de las tradiciones nacionales. A sus dos nietas -Julia y Agripina, que entonces no alcanzaban más de dos palmos de alto- se proponía consagrarlas a la virginidad y hacer de ellas vestales. Augusto tenía la costumbre de usar una coraza bajo su toga cuando iba al senado. (Albucius, 90)

Una de las caracterizaciones más logradas de este retrato tiene que ver también con un supuesto uso lingüístico, como es el de la paz convertida en silencio: 
Lo que él llamaba paz podría haberse llamado silencio. El silencio equivalía a encargar poemas y a pagarlos con viñas. El silencio, además de la poesía, era también el susurro que los muertos ya no podían emitir. (Albucius, 91)

En cualquier caso, Augusto se convierte, dentro de la creación de Quignard, en el verdadero autor del espíritu sórdido de su época, ahora no tanto representado por los poetas como por los cultivadores de un género, el retórico, que había perdido la grandeza de la gran oratoria ciceroniana para deleitarse en la sordidez como una forma de belleza.

\section{Conclusiones}

He propuesto en este trabajo las bases de una HnA de la figura de Augusto en la literatura y ensayo modernos desde unos presupuestos precisos: una Historia que acontece, que sigue un procedimiento interpretativo y que se articula en torno a tensiones varias. La selección llevada a cabo obedece al intento de encontrar tres ejemplos significativos que ilustren esta lectura alteracadémica: una lectura de la segunda mitad del siglo XIX, dominada por el problema religioso y el de la decadencia, otra lectura de mitad del siglo XX dominada por el pesimismo y una lectura más reciente dominada por la interpretación de una moral impuesta, que no es otra que la de la sordidez:

-Proudhon: Cristianismo como herencia augústea: la catolicidad -Broch: Virgilio frente a Augusto

-Quignard: Augusto y la nueva moral sexual: sordidez y espanto

Cabe cuestionar, como última reflexión, el alcance de estas valoraciones alteracadémicas que obedecen a parámetros bien diferentes de los que exige la investigación histórica. Al margen de esto, lo que parece innegable es su atractivo y audacia. 